\title{
Seismic Risk Assessment of the Railway Network of China's Mainland
}

\author{
Weihua Zhu ${ }^{1,2} \cdot K_{\text {Kai }}$ Liu $^{1,2} \cdot$ Ming Wang ${ }^{1,2} \cdot$ Elco E. Koks $^{3}$
}

Published online: 7 August 2020

(C) The Author(s) 2020

\begin{abstract}
Earthquakes pose a great risk to railway systems and services around the world. In China alone, earthquakes caused 88 rail service disruptions between 2012 and 2019. Here, we present a first-of-its-kind methodology to analyze the seismic risk of a railway system using an empirically derived train service fragility curve. We demonstrate our methodology using the Chinese railway system. In doing so, we generate a set of stochastic earthquake scenarios for China based on a national-scale seismicity model. Using disruption records, we construct an empirically grounded fragility curve that relates the failure probability of train services to peak ground acceleration. By combining the simulated earthquakes, the fragility curve, and empirical train flow data from 2016, we quantitatively assess the seismic impact and the risk faced by the Chinese railway system. The maximum train trip loss could reach 2400 trips in response to a single seismic event, accounting for $34 \%$ of the national daily train trips. Due to the spatially uneven daily train flow and seismicity distribution, the seismic impact on the railway system in different seismic zones is highly heterogeneous and does not always increase when the hazard intensity increases. More specifically, the results show that the railway lines located in the Qinghai-Tibet
\end{abstract}

Kai Liu

liukai@bnu.edu.cn

1 State Key Laboratory of Earth Surface Processes and Resource Ecology, Beijing Normal University, Beijing 100875, China

2 Academy of Disaster Reduction and Emergency Management, Faculty of Geographical Science, Beijing Normal University, Beijing 100875, China

3 Institute for Environmental Studies (IVM), Vrije Universiteit Amsterdam, $1081 \mathrm{HV}$ Amsterdam, The Netherlands and Xinjiang seismic zones exhibit the highest risk. The generated impact curves and the risk map provide a basis for railway planning and risk management decisions.

Keywords Chinese railway system - Fragility curve $\cdot$ Seismicity model $\cdot$ Seismic risk

\section{Introduction}

Globally, earthquakes cause major damage to railway infrastructure and can result in large disruptions of railway services. The global expected annual seismic direct damage of road and railway assets is estimated to be approximately 1.2 billion US dollars (Koks et al. 2019). Destructive earthquakes can twist railroad tracks and destroy railway stations, causing train disruptions and delays, thereby reducing the service function of the railway system (Yan et al. 2017). For example, the Ms 8.0 Wenchuan Earthquake on 12 May 2008 caused up to USD 10.2 billion in direct economic damage to transport infrastructure and a disruption of 12 days on the Baocheng Line (UNCRD 2008). The Eastern Japan Earthquake on 11 March 2011, damaged 5600 sites of the national railway system. It took nearly a month to restore the full railway service (Edwards et al. 2015). For moderate earthquakes, there may be no direct physical damage, but when the seismic peak ground acceleration (PGA) reaches a certain level, trains must be stopped for safety reasons. An example of no direct physical damage is the Ms 5.8 earthquake that hit Changning County, China, on 17 and 18 June 2019. While there was no structural damage to railway lines, there was a cancelation of 44 train trips. In China alone, over 88 rail service disruptions induced by earthquakes were reported from 2012 to 2019. In these 
disruptive events, less than $10 \%$ of the earthquakes caused physical damage to the railway system. To ensure safe operation and effective maintenance of railway infrastructure systems, it is both urgent and necessary to assess the seismic impact on train services and to identify railway lines with a high risk of seismicity-induced service disruptions.

Risk is conventionally defined as the product of the probability of a hazard and the consequential impact (Hall et al. 2003; Grossi 2005; Liu et al. 2018a). Earthquakes can cause considerable direct damage to railway components and indirect impact to transport services and economic activities. One line of research has focused on the direct damage to railroad tracks, embankments, and railway bridges. The estimation of direct damage usually involves fragility curves, which link the intensity of the hazard to the potential asset damage (Kiremidjian et al. 2007; Padgett et al. 2010; Koks et al. 2019). Kiremidjian et al. (2007), for example, assessed the expected cost of damage to a transportation system when subjected to a severe earthquake using a set of fragility curves. Padgett et al. (2010) estimated earthquake damage and losses to bridge infrastructure using region-specific bridge fragility curves. Another line of research has focused on indirect losses, which refer to losses caused by disruptions of the transportation system, resulting in disrupted passenger flows, increased trip times due to detours, and/or disruption of freight flows (Gong et al. 2017; Yan et al. 2017; Kilanitis and Sextos 2019). Kilanitis and Sextos (2019) and Yan et al. (2017) used structure-specific fragility curves to assess the operational loss to transportation systems following earthquakes. However, these studies may have largely underestimated the service loss when there is no direct physical damage under moderate earthquakes. It is therefore necessary to establish a fragility curve that can correctly represent the relation between the disruption probability and the PGA intensity to assess the seismic risk in terms of service loss.

This study developed a methodology to quantify the seismic impact and risk to railway system in terms of train trip loss, which can be caused by both physical damage and emergency shutdowns. The Chinese railway system is taken as an example to illustrate the methodology. In this analysis, stochastic earthquake scenarios are generated based on a seismicity model for China. A segment-level train service fragility curve is developed based on empirical record data from 2012 to 2019. The railway system is overlaid with seismic intensity maps to obtain the disruption state of each railway segment. Potential train trip losses are estimated using spatial analysis and complex network theory. The remainder of the article is organized as follows. Section 2 describes the seismic risk analysis framework, including the methodology on earthquake scenario generation, fragility curve development, and quantification of seismic impact and risk. Sections 3 and 4 apply the proposed framework to the Chinese railway system and present the main results. In Sects. 5 and 6, we discuss the results and conclude the article.

\section{Seismic Risk Analysis Framework}

In this section, we first propose an event-based seismic risk analysis framework. Then, we describe in detail the methods used in the framework, including the methodology on earthquake scenario generation, fragility curve development, and the quantification of seismic impact and risk.

\subsection{Event-Based Seismic Risk Analysis}

Generally, risk is quantified as the expected annual impact or loss (Winsemius et al. 2013), referring to the relationship between the probability or frequency of the hazard and a measure of the degree of the impact on a given asset (Nekrasova et al. 2015):

$R=\frac{\sum_{e}^{T-\mathrm{EC}} E\left(\mathrm{~s}, \mathrm{y}_{e}\right) H\left(\mathrm{y}_{e}\right) F\left(\mathrm{y}_{e}\right)}{T}$

where $R$ is the expected annual impact (risk); $e$ is an earthquake; $T-E C$ is an earthquake catalogue over $T$ years; $\mathrm{y}_{e}$ is the level of the hazard intensity of $e ; s$ is the target asset; $E\left(\mathrm{~s}, \mathrm{y}_{e}\right)$ is a measure of loss as a function of the asset state, potentially consisting of both direct impact (Argyroudis et al. 2015) and indirect impact (Kappos et al. 2014) associated with an event; $H$ is the hazard function; and $F$ is the fragility curve (Zuur et al. 2001), which we consider to be the disruption of train trips across a spectrum of hazard intensity.

In this study, we propose an event-based seismic risk assessment approach for a railway system, as shown in Fig. 1. The earthquake scenarios are generated based on a seismicity model in which the ground motion parameters are estimated for each earthquake (Box 1). This is followed by the development of a railway network with mapped train flows, representing railway exposure (Box 2). In the next step, we construct the failure fragility curve, which describes the failure probability of train services under different seismic intensity levels based on train disruption records (Box 3). The seismic risk of railway system is assessed in terms of expected annual train trip loss throughout the network (Box 4).

\subsection{Earthquake Hazard Simulation}

Earthquakes can be generated based on historical data (Yan et al. 2017), but also can be produced by a seismicity 
model, such as the seismicity model in the probabilistic seismic hazard assessment (PSHA) model (Cornell 1968). The seismicity model in the PSHA model uses potential seismic source zones (PSSZs) to identify areas where earthquakes tend to occur. The PSHA seismicity model satisfies three hypotheses:

1. The earthquake magnitude distribution in each PSSZ satisfies the truncated Gutenberg-Richter (G-R) relationship (Scholz 1968). The G-R relationship describes the number of earthquakes, $N(m)$, of a given magnitude, $m$, or greater, in a given period of time calculated by Eq. (2):

$\log N(m)=a-b m$

where $a$ and $b$ are empirical constants. The constants $a$ and $b$ are estimated using a statistical analysis of historical observations. The $a$ value indicates the overall rate of earthquakes in a region, and the $b$ value indicates the relative ratio of small to large magnitudes (typical $b$ values approximately equal to 1) (Baker 2008). There is generally a limit on the upper bound of earthquake magnitudes in each PSSZ, which is governed by the capacity of faults (Scholz 1968; Anagnos and Kiremidjian 1988). The lower magnitude bound is derived from practical considerations to exclude earthquakes that are unlikely to cause any structural damage.

2. The earthquake occurrence frequency in each PSSZ satisfies the Poisson distribution (Cornell 1968) as given in Eq. (3):
$P(n)=\frac{v_{i}^{n} \exp \left(-v_{i}\right)}{n !}$

where $P(n)$ is the probability of $n$ occurrences per year of earthquakes with a magnitude of $m_{i}$ or greater and $v_{i}$ is the related average annual frequency.

3. The spatial pattern of seismicity is represented by a uniform distribution in the PSSZ. For an event-based seismic risk assessment, long time series of seismic events are usually required to ensure that the expected risk estimation is more stable and accurate (Speight et al. 2017; Huang and Nivolianitou 2019). In this study, we use a Monte Carlo method to construct a $T$ year earthquake catalogue by generating a random number of $n$ occurrences based on the cumulative distribution function of $P(n)$.

To assess the seismic impact on railway systems, we need to know the ground motion associated with each earthquake. Peak ground acceleration can be used to represent the intensity level of each site and can be estimated by attenuation relationships using magnitude, distance, and other aspects of ground motion (Edwards et al. 2015; Yu 2015). Many countries have developed empirical attenuation relationships for PGA by using motion data from historical earthquakes (Albarello and D'Amico 2004; Mohanty et al. 2009), and these relationships can be used to estimate the degree of ground shaking during an earthquake.
Fig. 1 Methodology of assessing seismic impact and risk to railway system

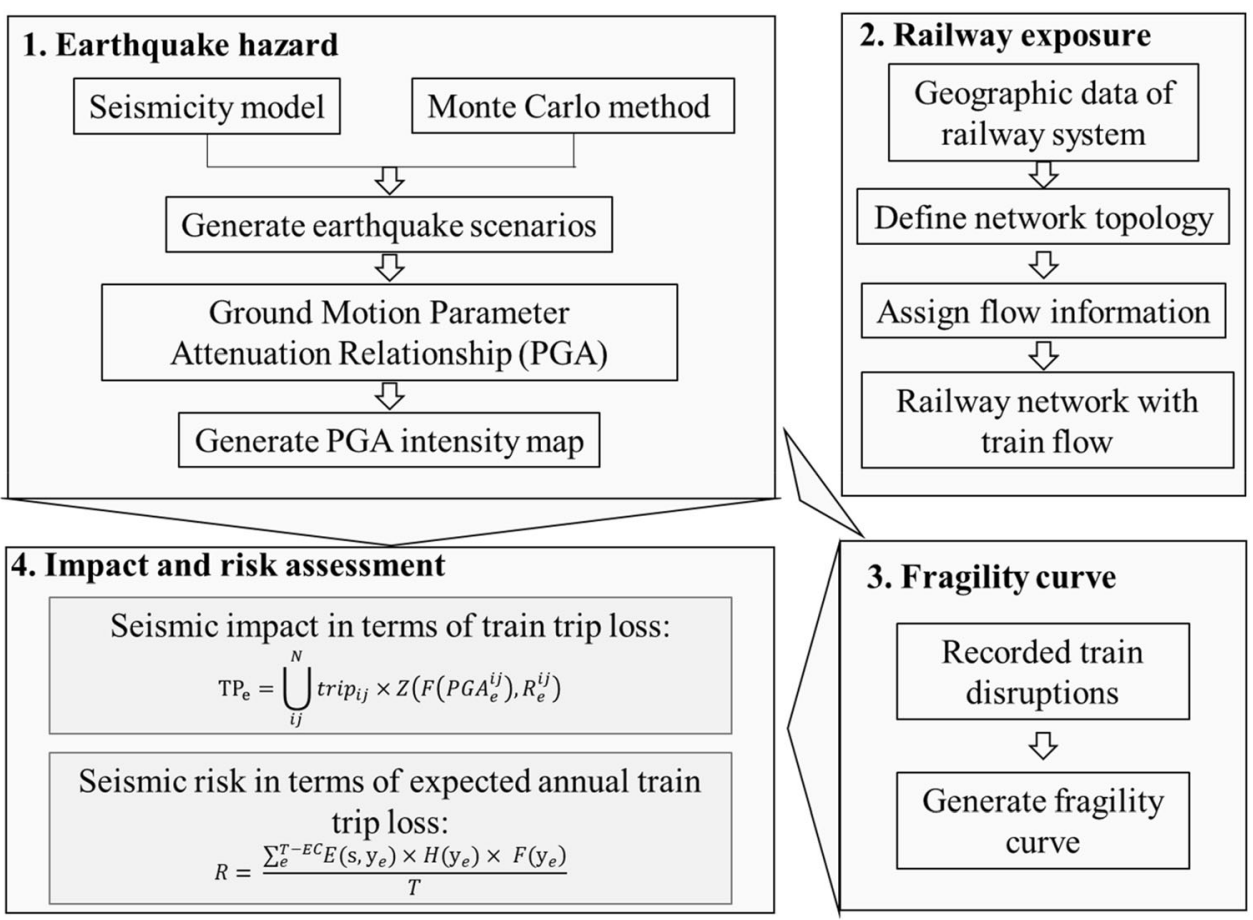




\subsection{Construction of the Fragility Curve}

An empirical fragility function is one that is created by fitting a function based on observed damage data for different components (Padgett et al. 2010; Park and Choi 2011; Argyroudis and Kaynia 2015). For railway networks, the number of train trips that will be affected by a hazard event is of particular importance for understanding the impact of the event. The fragility curve can be constructed based on the train disruption records, which is expressed as the failure probability of train services under different PGA intensity levels. To do this, we overlap the PGA intensity map of each historical earthquake that has disrupted train services and obtain the associated maximum PGA intensity of each railway segment between two stations. The failure probability of train services under different seismic intensity levels can be calculated as Eq. (4):

$P(P G A)=\frac{D L_{P G A}^{\max }}{L_{P G A}^{\max }}$

where $P(P G A)$ is the failure probability of train services under the given $P G A$ intensity level and $D L_{P G A}^{\max }$ and $L_{P G A}^{\max }$ are the disrupted and total number of railway segments between stations overlapped with the given PGA intensity, respectively. If the railway line crosses areas with different PGA intensities, only the maximum intensity is considered. The fragility curve $F(P G A)$ is derived by fitting the observed failure probabilities of train services using a leastsquares method.

\subsection{Seismic Impact and Risk Assessment}

As low seismic intensities may not lead to direct damage to the railway system but could affect their services, we use the expected annual train trip loss to express the seismic risk of the railway system, as shown in Eq. (5):

$A R_{s}=\frac{\sum_{e}^{T-\mathrm{EC}} T P_{e}}{T}$

where $A R_{S}$ is the seismic risk of the railway system, $T$-EC is the $T$-year earthquake catalogue, and $T P_{e}$ is the train trip loss under earthquake scenario $e$, which is defined in Eqs. (6) and (7):

$$
\begin{aligned}
& T P_{e}=\bigcup_{i j}^{N} \operatorname{trip}_{i j} Z\left(F\left(P G A_{e}^{i j}\right), R_{e}^{i j}\right) \\
& Z\left(F\left(P G A_{e}^{i j}\right), R_{e}^{i j}\right)=\left\{\begin{array}{l}
0, F\left(P G A_{e}^{i j}\right)<R_{e}^{i j} \\
1, F\left(P G A_{e}^{i j}\right) \geq R_{e}^{i j}, \quad R_{e}^{i j} \in[0,1]
\end{array}\right.
\end{aligned}
$$

where $T P_{e}$ is the train trip loss under earthquake scenario $e$ and trip $_{i j}$ is the train trips travelled through railway segment $l_{i j}$, which connects stations $i$ and $j . F$ is the fragility curve, and $P G A_{e}^{i j}$ is the maximum PGA level associated with $l_{i j}$ under earthquake scenario $e . R_{e}^{i j}$ is a random number that follows a uniform $(0,1)$ distribution. When $F\left(P G A_{e}^{i j}\right)$ $\geq R_{e}, l_{i j}$ is disrupted, and $Z\left(F\left(P G A_{e}^{i j}\right), R_{e}^{i j}\right)=1$; otherwise, $Z\left(F\left(P G A_{e}^{i j}\right), R_{e}^{i j}\right)=0$.

To assess the risk of different railway lines, we also calculate the risk associated with each railway segment, as given in Eq. (8):

$A R_{i j}=A F_{i j} f_{l o w}$

where $A F_{i j}$ is the annual failure probability, that is, annual disruption frequency. flow $_{i j}$ is the train trip flow of segment $l_{i j}$. The annual failure probability $A F_{i j}$ is calculated by Eq. (9):

$A F_{i j}=\frac{\sum_{e}^{T-\mathrm{EC}} Z\left(F\left(P G A_{e}^{i j}\right), R_{e}^{i j}\right)}{T}$

\section{Application to the Chinese Railway System}

The aforementioned methodology is applied to assess the seismic risk of the Chinese railway system. In this section, we first generate Chinese earthquake catalogues and associated intensity maps according to the seismicity model and the attenuation relationship. This is followed by the delineation of Chinese railway network with train flow and the construction of the failure fragility curve based on train disruption records from 2012 to 2019.

\subsection{Earthquake Scenario Generation}

We generate earthquake catalogues based on the CPSHA (Chinese probabilistic seismic hazard assessment) seismicity model developed by the Chinese State Seismological Bureau. For each earthquake, we use the attenuation relationship to get the intensity map that is used to assess the influence of earthquakes on the railway system.

\subsubsection{Seismicity Model}

According to the China Earthquake Administration (CEA 2015), China is divided into four seismic zones considering both regional characteristics of seismic activity levels and the zoning characteristics of seismic intensity attenuation (Fig. 2a): (1) the East strong seismic zone, (2) the moderate-strong seismic zone, (3) the Qinghai-Tibet seismic zone, and (4) the Xinjiang seismic zone. To assess the seismic impact of earthquakes on the Chinese railway system, we have generated seismic events in these different seismic zones based on the CPSHA seismicity model. The CPSHA seismicity model was developed by the Chinese State Seismological Bureau (Pan et al. 2003) on the basis 
of the PSHA method (Cornell 1968). The CPSHA seismicity model divides China and its adjacent areas into 29 seismic statistical zones (SSZs, the statistical unit of seismicity) (Fig. 2b) to represent the differences in seismicity between different regions according to historical data and geologic conditions (CEA 2015). Additionally, to account for the local seismic heterogeneity in SSZs, each SSZ is divided into several PSSZs, which present areas where earthquakes tend to occur. This results in a total of 1234 PSSZs, as shown in Fig. 2c. The seismicity parameters of the SSZ include the upper limit magnitude $\left(m_{u z}\right)$, the parameter in the G-R relationship $(b)$, and the average annual frequency of earthquakes with a magnitude of 4 or greater ( $v 4)$ (Table 1); these parameters are established using the statistical fitting method based on the historical earthquake data information and the spatial heterogeneity in the data.

As mentioned in Sect. 2.2, the magnitude distribution in each SSZ satisfies the truncated G-R recurrence relationship. Based on Eq. (2), the CPSHA seismicity model divides the magnitude domain into $N$ magnitude intervals and uses the formula to calculate the probability of $P\left(m_{j}\right)$ of the $j$ th magnitude interval defined as Eq. (10):
$P\left(m_{j}\right)=\frac{2 \exp \left[-\beta\left(m_{j}-m_{i}\right)\right]}{1-\exp \left[-\beta\left(m_{u z}-m_{i}\right)\right]} \operatorname{sh}\left(\frac{\beta}{2}\right) \Delta m$

where $m_{j}$ and $\Delta m$ are the central value and magnitude interval of the $j$ th magnitude interval $m_{j}-\frac{1}{2} \Delta m \leq m_{j} \leq m_{j}+\frac{1}{2} \Delta m$, respectively. $\beta$ is calculated as $b \ln 10, b$ is the parameter in the $\mathrm{G}-\mathrm{R}$ relationship of each SSZ, and the value of $b$ can be found in Table 1; sh denotes a sine hyperbolic function; $m_{i}$ is the lower limit magnitude, corresponding to a magnitude of 4 in the CPSHA seismicity model; and $m_{u z}$ is the upper limit magnitude of each SSZ, corresponding to magnitudes $8.5,7.5,9$, and 8.5 in the East strong seismic zone, moderate-strong seismic zone, Qinghai-Tibet seismic zone, and Xinjiang seismic zone, respectively. The value of $b$ remains constant when the magnitude interval is less than 0.5 ; in this study, a magnitude interval of 0.5 is chosen for $\Delta m$. Based on Eq. (10), the probability of magnitude exceedance curves for the 27 SSZs are shown in Fig. 2d.

The earthquake occurrence frequency in each SSZ satisfies the Poisson distribution as given in Eq. (3), and the values of parameter $v 4$ for different SSZs are given in Table 1. Based on the third assumption presented in Sect. 2.2, the occurrence of seismic events is not uniformly

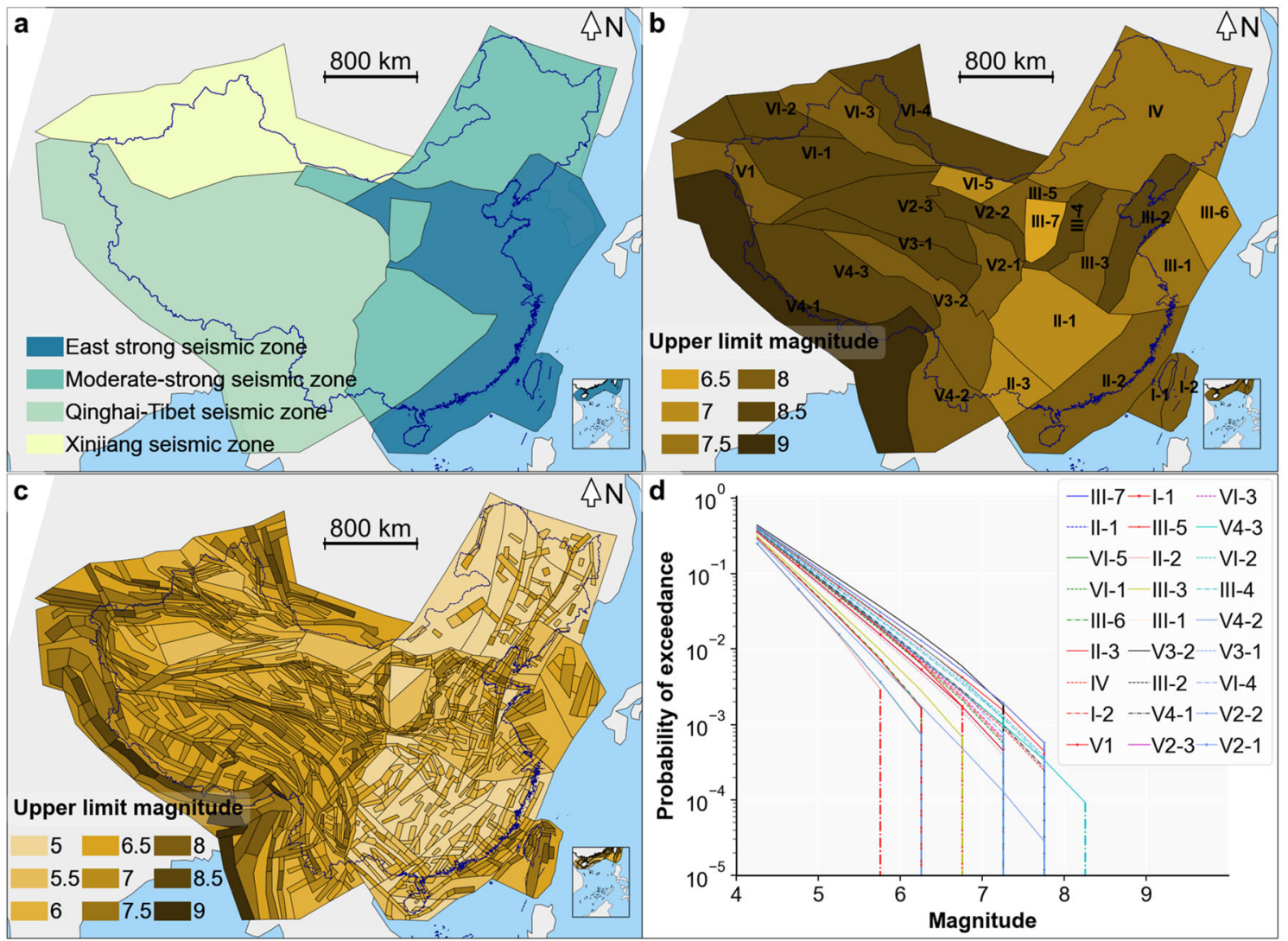

Fig. 2 Chinese probabilistic seismic hazard assessment (CPSHA) seismicity model. a Distribution of seismic zones; b distribution of seismic statistical zones (SSZ); c distribution of potential seismic source zones (PSSZ) and d probability of magnitude exceedance curves for the 27 SSZs 
Table 1 Parameters of the seismic statistical zones

\begin{tabular}{|c|c|c|c|c|c|}
\hline ID & Seismic statistical zone (SSZ) & $m_{u z}$ & $b$ & $v_{4}$ & $\begin{array}{l}\text { Ground motion attenuation } \\
\text { relationship region (PGA) }\end{array}$ \\
\hline $\mathrm{I}-1$ & Western Taiwan SSZ & 8 & 0.9 & 22 & East strong seismic zone \\
\hline $\mathrm{I}-2$ & Eastern Taiwan SSZ & 8 & 0.92 & 107 & East strong seismic zone \\
\hline II-1 & The middle reaches of the Yangtze River SSZ & 7 & 1.2 & 3.2 & Moderate-strong seismic zone \\
\hline II-2 & South China coastal SSZ & 8 & 0.87 & 5.6 & East strong seismic zone \\
\hline II-3 & Youjiang SSZ & 7 & 1.04 & 2.5 & Moderate-strong seismic zone \\
\hline III-1 & $\begin{array}{l}\text { The south Yellow Sea in the lower reaches of } \\
\text { the Yangtze River SSZ }\end{array}$ & 7.5 & 0.85 & 3 & East strong seismic zone \\
\hline III-2 & Tanlu SSZ & 8.5 & 0.85 & 4 & East strong seismic zone \\
\hline III-3 & North China Plain SSZ & 8 & 0.86 & 4.6 & East strong seismic zone \\
\hline III-4 & Fenwei SSZ & 8.5 & 0.78 & 2.5 & East strong seismic zone \\
\hline III-5 & Yinchuan Hetao SSZ & 8 & 0.9 & 4.5 & East strong seismic zone \\
\hline III-6 & North Korea SSZ & 7 & 1.05 & 2 & East strong seismic zone \\
\hline III-7 & Ordos SSZ & 6.5 & 1.2 & 1 & Moderate-strong seismic zone \\
\hline IV & Northeast SSZ & 7.5 & 1 & 5 & Moderate-strong seismic zone \\
\hline V1 & West Kunlun Pamir SSZ & 8 & 0.92 & 50 & Qinghai-Tibet seismic zone \\
\hline V2-1 & Longmen Mountain SSZ & 8 & 0.71 & 5.2 & Qinghai-Tibet seismic zone \\
\hline V2-2 & Liupan Mountain Qilian Mountain SSZ & 8.5 & 0.75 & 6.4 & Qinghai-Tibet seismic zone \\
\hline V2-3 & Qaidam Alkin SSZ & 8.5 & 0.84 & 12 & Qinghai-Tibet seismic zone \\
\hline V3-1 & Bayan Har Mountains SSZ & 8.5 & 0.75 & 6.5 & Qinghai-Tibet seismic zone \\
\hline V3-2 & Xishuihe east dian SSZ & 8 & 0.85 & 32 & Qinghai-Tibet seismic zone \\
\hline V4-1 & Himalaya SSZ & 9 & 0.85 & 83 & Qinghai-Tibet seismic zone \\
\hline V4-2 & Southwest Yunnan SSZ & 8 & 0.77 & 20 & Qinghai-Tibet seismic zone \\
\hline V4-3 & Central Tibetan SSZ & 8.5 & 0.81 & 25 & Qinghai-Tibet seismic zone \\
\hline VI-1 & South Tianshan SSZ & 8.5 & 1.1 & 44 & Xinjiang seismic zone \\
\hline VI-2 & Mid-Tianshan SSZ & 8.5 & 0.8 & 7 & Xinjiang seismic zone \\
\hline VI-3 & North Tianshan SSZ & 8 & 0.83 & 9 & Xinjiang seismic zone \\
\hline VI-4 & Altai Mountains SSZ & 8.5 & 0.75 & 7 & Xinjiang seismic zone \\
\hline VI-5 & Alashan, Tarim SSZ & 7 & 1.2 & 1.6 & Moderate-strong seismic zone \\
\hline
\end{tabular}

$m_{u z}$, The upper limit magnitude; $b$, The parameter in the G-R relationship; $v 4$, The average annual frequency of earthquakes with a magnitude of 4 or greater

distributed in a SSZ, but is uniformly distributed in each PSSZ. Due to a lack of empirical information on the occurrence of seismic events in the SSZs, we allocate the generated seismic events in each SSZ to PSSZs based on historical earthquake data from 1900 to 2019 (USGA) according to Eq. (11):

$P\left((x, y)_{i} \mid m_{j}\right)_{s s z}=\frac{N e_{i}^{j}}{\sum_{i}^{n 0} N e_{i}^{j}}$

where $P\left((x, y)_{i} \mid m_{j}\right)$ is the occurrence possibility of seismic events with magnitude $m_{j}$ of each site in one PSSZ, $(x, y)$ is the site location, $m_{j}$ is the earthquake magnitude, $N e_{i}^{j}$ is the number of historical seismic events with magnitude $m_{j}$ in the $i$ th PSSZ, and $n 0$ is the total number of PSSZs in one SSZ.
To assess the expected annual train trip loss to the national railway system, we generate a 1000-year earthquake catalogue for China. First, we use a Monte Carlo method to generate a random number of occurrences for each year based on the cumulative distribution function of $P(n)$ of each SSZ. Based on the G-R relationship given in Eq. (10), the magnitude of each seismic event can be determined. Next, we allocate these seismic events into PSSZs based on Eq. (11). To assess the seismic impact of different magnitudes in each seismic zone, we further generate 10,000 seismic events for each magnitude interval in different seismic zones. The total number of generated events in each seismic zone is given in Table 2, which is determined by the lower and upper limit magnitude of each SSZ. 
Table 2 Number of seismic events in each seismic zone

\begin{tabular}{lllll}
\hline & East strong seismic zone & Moderate-strong seismic zone & Qinghai-Tibet seismic zone & Xinjiang seismic zone \\
\hline Upper limit magnitude & 8.5 & 7.5 & 9 & 8.5 \\
Number of events & 90,000 & 70,000 & 100,000 & 90,000 \\
\hline
\end{tabular}

Table 3 Parameters of the peak ground acceleration of seismic zones

\begin{tabular}{|c|c|c|c|c|c|c|c|c|c|}
\hline \multirow[t]{3}{*}{ PGA of seismic zone } & \multirow[t]{3}{*}{ Axis } & \multicolumn{7}{|c|}{ Regression coefficients } & \multirow{3}{*}{$\begin{array}{l}\text { Standard deviation } \\
\sigma\end{array}$} \\
\hline & & \multicolumn{2}{|l|}{$\mathrm{A}$} & \multicolumn{2}{|l|}{$\mathrm{B}$} & \multirow{2}{*}{$\begin{array}{l}\mathrm{C} \\
\mathrm{C}\end{array}$} & \multirow{2}{*}{$\begin{array}{l}\mathrm{D} \\
\mathrm{D}\end{array}$} & \multirow{2}{*}{$\begin{array}{l}\mathrm{E} \\
\mathrm{E}\end{array}$} & \\
\hline & & $\leq \mathrm{M} 6.5$ & $>$ M6.5 & $\leq \mathrm{M} 6.5$ & $>$ M6.5 & & & & \\
\hline \multirow[t]{2}{*}{ East strong seismic zone } & Major Axis & 1.979 & 3.533 & 0.671 & 0.432 & -2.315 & 2.088 & 0.399 & 0.236 \\
\hline & Minor Axis & 1.176 & 2.753 & 0.66 & 0.418 & -2.004 & 0.944 & 0.447 & 0.236 \\
\hline \multirow[t]{2}{*}{ Moderate-strong seismic zone } & Major Axis & 2.417 & 3.706 & 0.498 & 0.298 & -2.079 & 2.802 & 0.295 & 0.236 \\
\hline & Minor Axis & 1.715 & 2.69 & 0.471 & 0.321 & -1.723 & 1.295 & 0.331 & 0.236 \\
\hline \multirow[t]{2}{*}{ Qinghai-Tibet seismic zone } & Major Axis & 2.387 & 3.807 & 0.645 & 0.411 & -2.416 & 2.647 & 0.366 & 0.236 \\
\hline & Minor Axis & 1.003 & 2.457 & 0.609 & 0.388 & -1.854 & 0.612 & 0.457 & 0.236 \\
\hline \multirow[t]{2}{*}{ Xinjiang seismic zone } & Major Axis & 1.791 & 3.403 & 0.72 & 0.472 & -2.389 & 1.772 & 0.424 & 0.236 \\
\hline & Minor Axis & 0.983 & 2.61 & 0.713 & 0.463 & -2.118 & 0.825 & 0.465 & 0.236 \\
\hline
\end{tabular}

The attenuation relationship that describes the main direction of energy propagation and the relation between the semi-axes of the ellipse in two orthogonal directions (major axis: minor axis) (Douglas 2019)

\subsubsection{Generation of the Earthquake Peak Ground Acceleration Intensity Map}

To assess the influence of earthquakes on the railway system, intensity maps need to be generated for each seismic event (Argyroudis et al. 2015). The relationship that describes the correlation between the local ground movement intensity of the earthquake magnitude and the distance from the earthquake's epicenter is given in Eq. (12) (Yu 2015). This relationship fully absorbs the latest research results of the attenuation relationship (Irwansyah et al. 2013) of ground motions from China and elsewhere and considers the actual situation and engineering practice of China's strong motion data (Yu 2015).

$\log Y=A+B M+C \log \left(R+D e^{E M}\right)$

where $Y$ is the PGA intensity, $M$ is the magnitude of the earthquake, $R$ is the distance from the epicenter $(\mathrm{km})$, and $A, B, C, D$, and $E$ are regression coefficients, which are derived from historical earthquake data based on a statistical regression method (Yu 2015). The parameters for the four seismic zones are shown in Table 3.

\subsection{Chinese Railway Network and Its Fragility}

We construct a topological network of Chinese railway system and assign train flow to the network with the information provided by China railway customer service center. ${ }^{1}$ Based on the historical disruptions of train services, we establish the fragility curve of Chinese railway system according to the method presented in Sect. 2.3.

\subsubsection{The Chinese Railway Network}

In 2018, the total length of railway tracks in China reached $131,000 \mathrm{~km}$. The railway system had 2240 railway stations and transported 3.37 billion passengers in that year. In this study, we model the Chinese railway system as a network, where we use nodes to represent railway stations and edges to represent railway tracks. The average daily train flow between two stations is assigned to each edge. Two datasets are used to build the network: (1) geographic data of railway stations and lines from OpenStreetMap, ${ }^{2}$ which provides geographical information on railway segments; and (2) timetable data from the China railway customer service center (see footnote 1), providing complete information on the daily number of passenger trains and their routes for the entire Chinese rail network. The topological network is defined using the space $\mathrm{L}$ method (Sen et al. 2003). The space $L$ network topology uses nodes to represent railway stations and edges to represent rail lines

\footnotetext{
1 https://www.12306.cn/index/.

2 https://www.openstreetmap.org.
} 


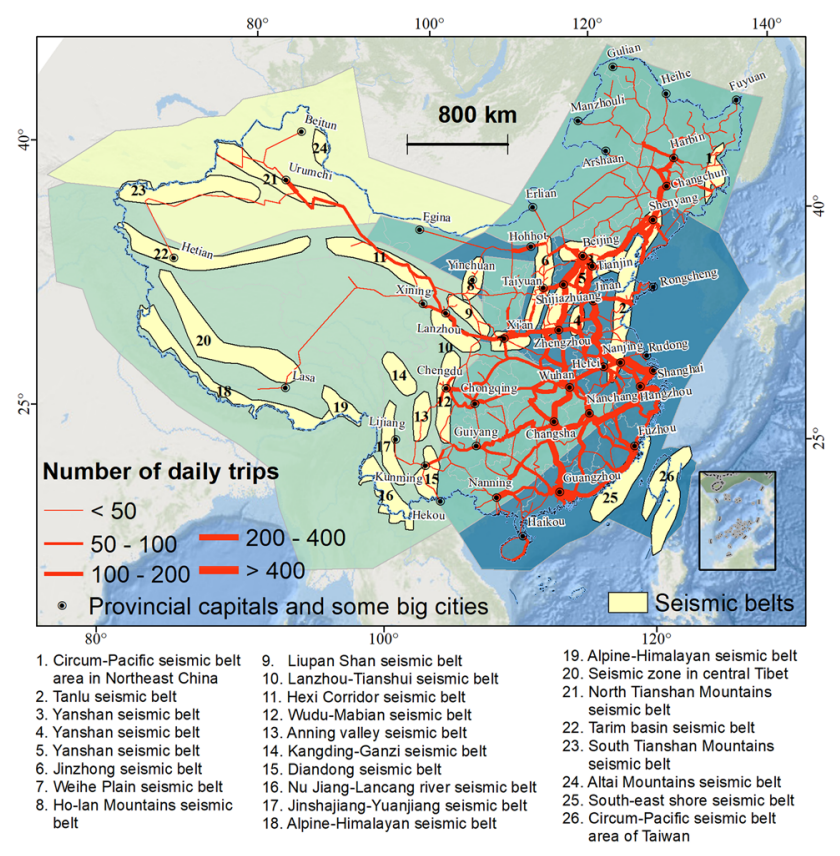

Fig. 3 Chinese railway network and the distribution of daily train trips, 2016

between two consecutive sites, where multiple links do not exist between two consequential nodes. Multiple stations in the same city, such as Beijing Station and Beijing South Station, are combined into one node for simplicity. The station with the largest transport capacity is defined as the location of stations in the same city. Due to the nationalscale focus of our study, this has little impact on our results. The final extracted railway network consists of 1973 edges and 1790 nodes. Figure 3 presents the spatial distribution of the average daily passenger train numbers through the nodes and their associated edges, for a total of 7115 train trips every day. It is obvious that both the topology and traffic flows have large spatial variations, and there is a clear decreasing trend of network density from the eastern coastal area to the western area. A total of 5541, 3396, 823, and 131 train trips pass through the East strong seismic zone, Moderate-strong seismic zone, Qinghai-Tibet seismic zone, and Xinjiang seismic zone, respectively. Furthermore, the lines that connect major cities, such as Beijing-Guangzhou, Beijing-Shanghai, and Beijing-Harbin, have larger traffic flows than those of other lines.

\subsubsection{Earthquake-Induced Train Disruptions and Fragility Curve}

Train disruptions caused by earthquakes provide a basis for understanding and modeling the distribution of seismic impact and the susceptibility of railway infrastructure (Liu et al. 2018b). From 2012 to 2019, China and its adjacent areas experienced 2788 earthquakes of magnitude 4.5 or greater (USGS) and a total of 88 train disruptions in China, as shown in Fig. 4a. The results show that the Chinese railway lines suffered widespread earthquake damage, particularly in the western Lanzhou-Tianshui seismic belt, Wudu-Mabian seismic belt, and Diandong seismic belt and South-east shore seismic belt. Figure $4 \mathrm{~b}$ shows the frequency-magnitude distribution of earthquakes that caused train disruptions between 2002 and 2019. We can see that train disruptions were induced by earthquakes with magnitudes greater than 4.5 .

The fragility curve is established based on the train disruption records according to the method presented in Sect. 2.3. The failure probability of train services under different seismic intensity levels is shown in Table 4. The fragility curve $F(P G A)$ given in Eq. (13) is derived using a least-squares fitting method based on the observed failure probability of train services and is presented in Fig. 5. As expected, the failure probabilities of train services increase with increasing PGA. We must mention that the fragility curve only works for earthquakes with magnitudes larger than 4.5 based on our historical observations because no disruptions were observed with lower magnitudes. The constructed fragility curve allows us to determine the failure status of the railway line in response to an earthquake and quantify the seismic risk of the railway system.

$F(P G A)=0.3026 \ln (P G A)+0.0955 m \geq 4.5$

\section{Results}

In this section, we assess the seismic impact and risk to Chinese railway system. We first investigate the impact of earthquakes with different magnitudes in different seismic zones, then identify the risk hotspots, and finally quantify the risk of the Chinese railway system.

\subsection{Impact Analysis}

Figure 6 shows the ratio of disruptive earthquakes in the generated earthquake scenarios, that is, 10,000 seismic events for each magnitude interval in four seismic zones. Disruptive earthquakes in this study indicate earthquakes that cause disruptions of train services. We can find that due to the spatially imbalanced railway topology and seismicity distribution, the ratio of disruptive earthquakes in different seismic zones is highly heterogeneous, and the ratio does not always increase when the hazard intensity increases. The disruptive earthquake ratio in the moderatestrong seismic zone is the highest since this area has a dense and evenly distributed railway network, as shown in Fig. 3. For the East strong and moderate-strong seismic zones, the disruptive earthquake ratio generally increases as the magnitude increases. Taking the East strong seismic 


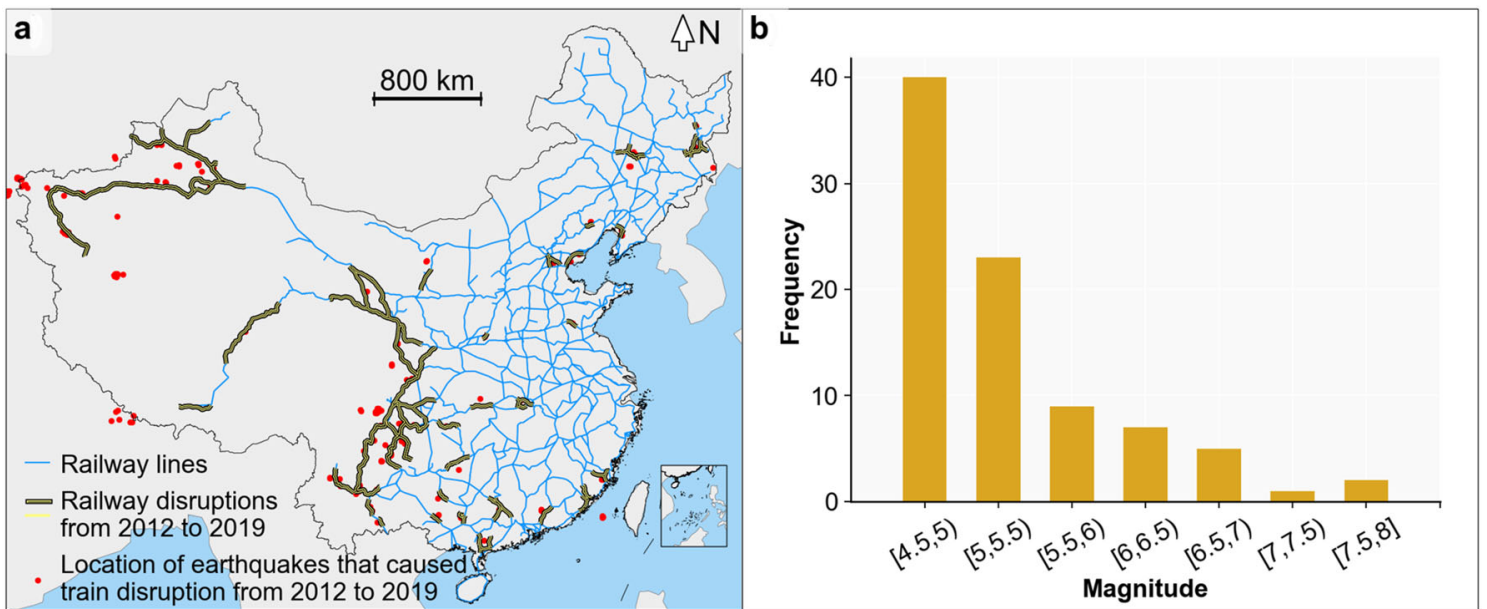

Fig. 4 Train disruptions induced by earthquake hazards, 2012-2019. a Spatial distribution of train disruptions and corresponding earthquakes and $\mathbf{b}$ frequency-magnitude distribution of earthquakes that caused train disruptions

Table 4 Failure probability of the railway segments under different maximum peak ground acceleration (PGA), 2012-2019

\begin{tabular}{lccc}
\hline Maximum PGA (gal) & Number of railway segments & Number of failed railway segments & Failure probability \\
\hline 5 & 454 & 60 & 0.13 \\
10 & 141 & 41 & 0.29 \\
15 & 76 & 30 & 0.39 \\
20 & 57 & 27 & 0.47 \\
25 & 29 & 18 & 0.62 \\
30 & 21 & 12 & 0.57 \\
35 & 15 & 11 & 0.73 \\
40 & 11 & 8 & 0.73 \\
45 & 11 & 9 & 0.82 \\
50 & 110 & 84 & 0.76 \\
\hline
\end{tabular}

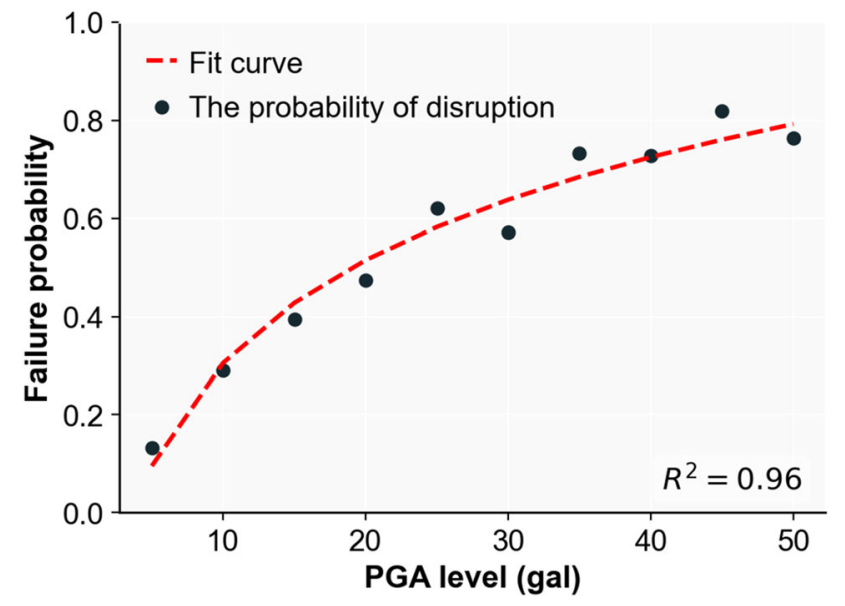

Fig. 5 The generated failure fragility curve of train services. $P G A$ peak ground acceleration

zone as an example, from magnitude 4.5 to 8 , the ratio of disruptive earthquakes increases approximately five times.
Earthquakes with magnitudes of 8-8.5 almost inevitably cause train disruptions. For the Qinghai-Tibet seismic zone, the disruptive earthquake ratio decreases when the earthquake magnitude reaches a certain value because the location of earthquakes with a magnitude of 7.5-9.0 in this seismic zone is far from railway lines, resulting in a low probability disruption ratio at higher earthquake magnitudes. The results reveal that seismic impact relies on both network topology distribution and seismicity distribution.

Figure 7 shows the seismic impact on train services for the four seismic zones. By comparing the results, we find that the maximum train trip loss under extreme earthquakes in different seismic zones is very different, and losses in the East strong seismic zone are larger than those in the other three zones. In the East strong seismic zone, the maximum train trip loss due to a single seismic event is close to 2400 (34\% of national daily train trips), which is three times that of the Moderate-strong seismic zone, 12 times that of the Qinghai-Tibet seismic zone, and 60 times 
that of the Xinjiang seismic zone. This is because the daily train flow in the eastern coastal area is significantly higher than those in inland areas, as shown in Fig. 3.

Due to the spatially imbalanced daily train flow and seismicity distribution, the median train trip loss does not always increase when the hazard intensity increases. In the Moderate-strong seismic zone, the median train trip loss increases as the magnitude increases, as shown in Fig. 7b. From magnitude 4.5 to 7.5 , the median train trip loss for one seismic event grows by approximately 11 times, from $20(0.28 \%$ of daily train trips) for $4.5-5$ magnitude earthquakes to 220 (3.1\% of daily train trips) for 7-7.5 magnitude earthquakes. The median train trip loss in the East strong seismic zone first increases from 100 (1.4\% of daily train trips) for 4.5-5 magnitude earthquakes to 350 (4.9\% of daily train trips) for 6.5-7 magnitude earthquakes and then decreases to 250 (3.5\% of daily train trips) for 7.5-8 magnitude earthquakes. In the Qinghai-Tibet and Xinjiang seismic zones, the median train trip loss remains almost constant at 18 and 12, respectively, for different magnitude intervals. In addition, in each seismic zone, the train trip loss in the magnitude intervals approximately obeys an exponential distribution, which indicates that most earthquakes produce little impact, while a few earthquakes can cause large amounts of loss. Our results reveal the importance of integrating hazard intensity, local network topology, and the spatial distribution of train flow, and the spatial coupling of the two when performing a seismic impact analysis.

\subsection{Risk Assessment}

Annual failure probability and risk of the Chinese railway system based on the 1000-year earthquake catalogue are presented in Fig. 8a, b, respectively. The results show that

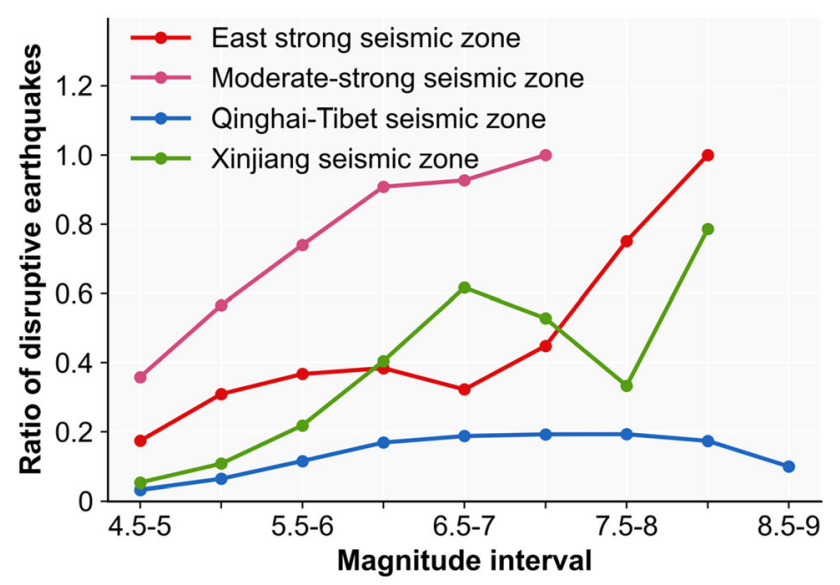

Fig. 6 Ratio of disruptive earthquakes in different peak ground acceleration zones the national railway lines prone to earthquake hazards are geographically widespread, especially in the west, southwest, and southeastern coast of China and the North China Plain. For approximately $7 \%$ of the railway lines $(9513 \mathrm{~km})$, the annual failure probability is greater than $10 \%$. The annual failure probability map has a good correspondence with the train disruptions from 2012 to 2019, as shown Fig. 4a. The high failure probability of the railway lines in western China is directly related to the strong deformation occurring on the Qinghai-Tibet Plateau. The railway lines along the South China coast are influenced by the movement of the Philippine Sea Plate and the Eurasian Plate.

The risk, that is, the expected annual train trip loss, of the national railway lines caused by the failure of each railway segment is assessed according to Eq. (8) and presented in Fig. 8b. We can see that the higher risk links, including Beijing-Wuhan, Xuzhou-Baoji, and XiamenGuangzhou, have low failure probabilities but high train trip flow, which places them in the high-risk category. Additionally, lines with higher failure probabilities but lower flows, such as Xian-Lasa, Chengdu-Kunming, and Urumchi-Hetian, also exhibit a higher overall risk. Lines in South China, such as Wuhan-Guangzhou, generally have moderate risk levels because of their high travel flows but especially low failure probabilities.

The annual train trip loss of the Chinese railway system is presented in Fig. 9, which shows the total train trip loss per year. The expected train trip loss of the national railway system is 955 ( $0.037 \%$ of the total annual train trips), and the average disruptive earthquakes are 12.2 per year. The results show that there is a $50 \%$ chance that 312 trips ( $0.012 \%$ of total annual train trips) will be disrupted by earthquakes in 50 years to the railway system. In addition, the disruption of at least 844 trips $(0.032 \%$ of total annual train trips) and 2178 trips $(0.084 \%$ of total annual train trips) has a probability of exceedance (PE) of $10 \%$ and 5\%, respectively, in 50 years. From the annual train trip loss curves of the four seismic zones, we can see that the absolute risk is the highest in the East strong seismic zone. The expected annual train trip loss is 675 in the East strong seismic zone- $0.033 \%$ of the total annual train trips passing through this zone. While the Xinjiang seismic zone experiences the highest relative risk to train services, the expected annual train trip loss is 41 , which corresponds to approximately $0.085 \%$ of the total annual train trips passing through this zone. 

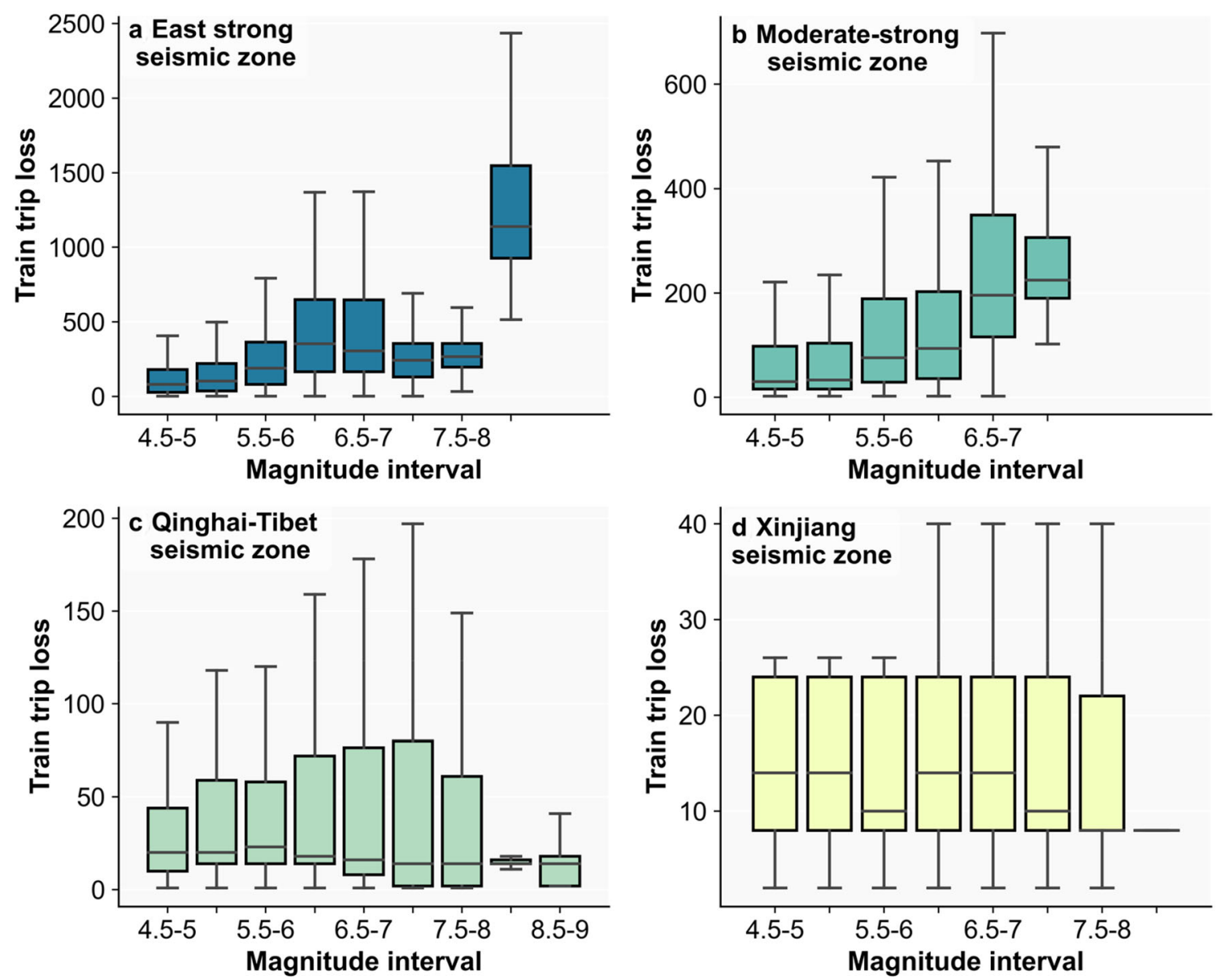

Fig. 7 Seismic impact on train services in different seismic zones: a East strong seismic zone; b moderate-strong seismic zone; c Qinghai-Tibet seismic zone; and d Xinjiang seismic zone. The

\section{Discussion}

This is one of the first studies to use train service fragility curves to assess the seismic impact and risk to a railway system. The results show that the expected annual train trip loss of the Chinese railway system in response to earthquakes is 955 , which is $0.037 \%$ of the annual train trips (7115 daily train trips $\times 365$ days, data from 2016). This loss is larger than that in the study of Yan et al. (2017), in which the expected annual train trip loss was estimated to be approximately $0.001 \%$ of annual train trips (4197 daily train trips $\times 365$ days, data from 2010). Neglecting changes in train trips and topology of the Chinese railway system, the expected ratio of disrupted trains given by our results is approximately 37 times larger than Yan's results. The difference is that in their study, trains were considered disrupted when the railway infrastructure was physically damaged. From the train disruption records of the Chinese railway system between 2012 and 2019, only $10 \%$ of disruption events were due to physical damage to structures, and approximately $90 \%$ of disruptions were caused by

boxplots present the full distribution of disruptive earthquake data, with lines corresponding to the 25th percentile, the median trip loss value, and the 75 th percentile

safety considerations following an earthquake. This result reveals the importance of incorporating a train service fragility curve in assessing the seismic risk of railway systems.

Based on our simulations, the average annual number of train disruptions is approximately 12 , which is close to that of train disruption records between 2012 and 2019 (an average of 11 disruptions per year). In addition, the annual failure probability map (Fig. 8a) shows a spatial pattern similar to that of the recorded train disruptions (Fig. 4a). Hence, in comparison with observations, our generated train service fragility curve appears robust in terms of both the annual number and spatial distributions of train disruptions.

A number of limitations are acknowledged in this analysis. First, with the lack of detailed seismicity information on the PSSZs in each SSZ, this study allocated the generated seismic events to PSSZs based on historical records. Since there are fewer recorded seismic events with extremely large magnitudes, this may lead to an inaccurate distribution of extreme seismic events. Second, the 


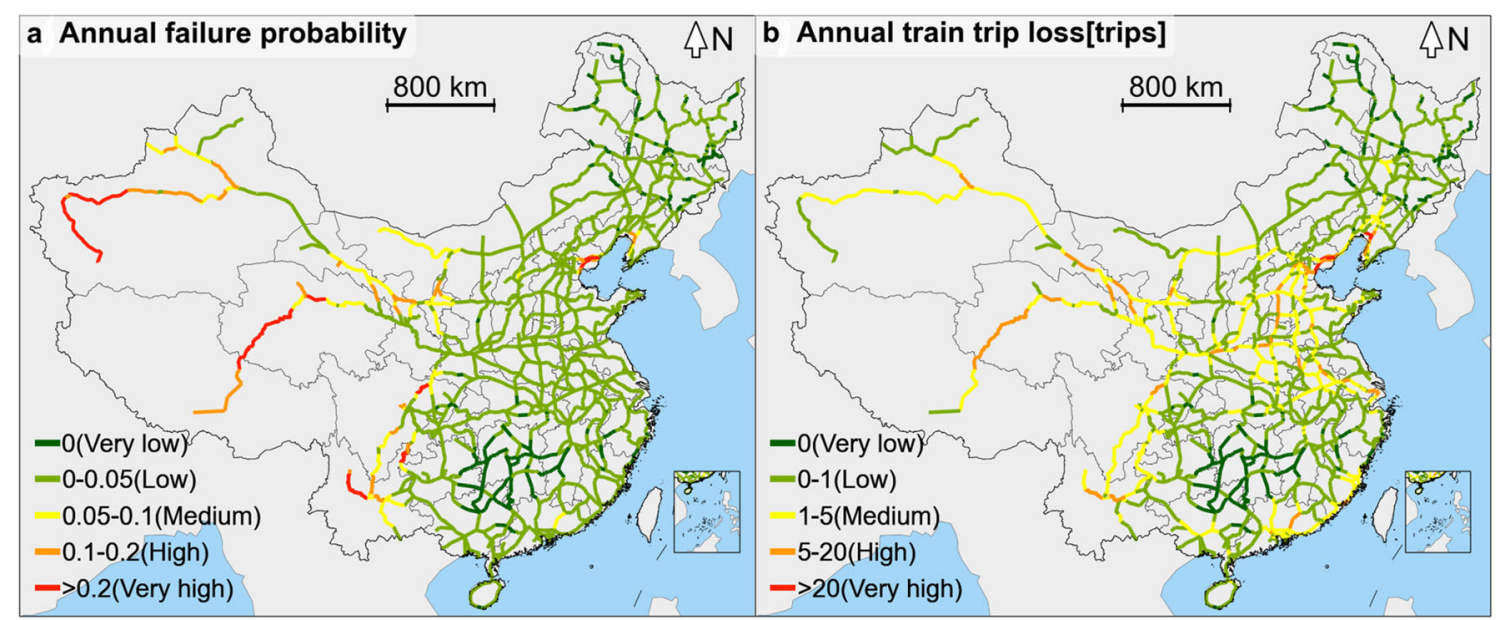

Fig. 8 Annual failure probability (a) and risk (b) of the Chinese railway system

disruption time is assumed to be 1 day in this study due to the lack of recorded data. For train disruptions caused by safety concerns, which accounted for $90 \%$ in this study, a 1-day disruption is reasonable. However, for the $10 \%$ of the disruptions caused by physical damage to railway infrastructures, this may underestimate the train trip loss.

As the main form of transport for travel and trade, train trip loss is merely one impact caused by earthquakes; more important is the consequential socioeconomic impact when trains are disrupted. In future work, the analysis could be extended and combined with macroeconomic impact assessment models (Yamano et al. 2007; Wu et al. 2012; Merz et al. 2013; Koks and Thissen 2016) to evaluate the economic losses caused by service disruptions (Arrighi et al. 2017; Pregnolato et al. 2017). A more accurate service loss modeling approach is the first step towards looking at socioeconomic impact and performing adaptation prioritization studies. In addition, the methodology proposed can be extended to other types of networks. Taking the highway network as an example, traffic disruptions occur when roads are damaged. The structural damage vulnerability curve (Argyroudis and Kaynia 2015) can be introduced to obtain the failure probability of roads under different seismic intensity levels. Although the road network does not have fixed trips and journeys like the railway network, the road management department usually provides the average passenger and goods flow in highways for every quarter of a year, which provides a basis for a risk assessment.

\section{Conclusion}

This study presents a comprehensive framework for the seismic impact and risk assessment of railway systems. The framework couples simulated earthquake hazards, an

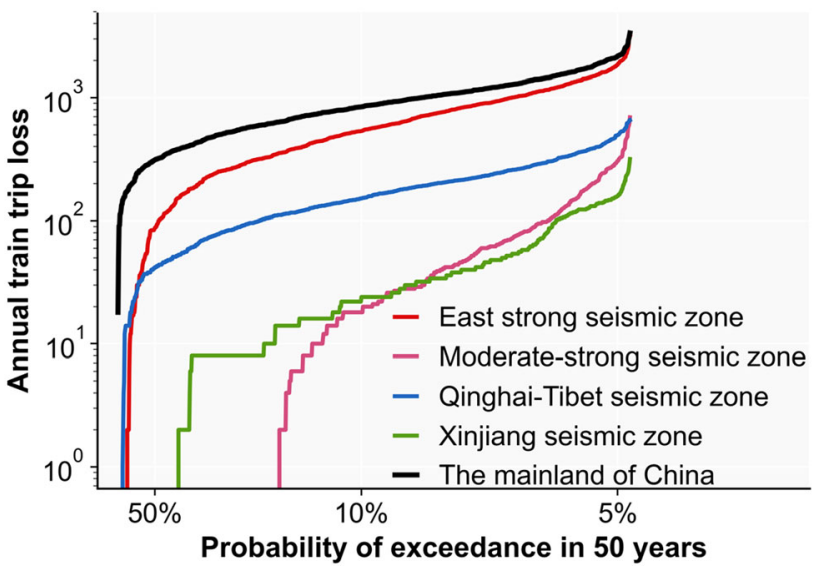

Fig. 9 Annual train trip loss of the Chinese railway system

empirically grounded failure disruption function, and complex network analysis to measure the impact of disruptions caused by earthquakes. Through this novel framework, we quantitatively assessed the seismic impact and the risk faced by the Chinese railway system.

Different from most existing work that only deals with train trip loss caused by structural damages, we estimated train trip loss from each seismic event based on the empirically derived train service fragility curve. The results obtained from this study show 37 times higher expected annual train trip loss than those obtained with the traditional approach. This is because most of the disruptions were caused by safety considerations following an earthquake instead of physical damage to structures. The maximum train trip loss could reach 2400 trips in response to a single seismic event, accounting for $34 \%$ of the national daily train trips. Such results provide the starting point for developing emergency plans or informing decisive actions on investments in preventive and adaptive measures. We further found that the regional seismic impact on the 
Chinese railway system is highly heterogeneous. This is the result of the spatially uneven railway topology, traffic flow, and hazard intensity distribution across China. The absolute expected annual train trip loss is the highest in the East strong seismic zone, and the relative expected annual train trip loss is the highest in the Xinjiang seismic zone. In addition, the seismic impact does not always increase with increasing earthquake magnitude in the Qinghai-Tibet and Xinjiang seismic zones because of the scattered distribution of the railway lines and the distance between the epicenters of high-magnitude earthquakes and the railway lines. The results can help prioritize areas where natural hazard risk management interventions are most needed to reduce the system vulnerability and to secure the safety and robustness of railway operations.

Acknowledgements The research for this article was supported by the National Key Research and Development Plan (2018YFC1508802), National Natural Science Foundation of China (41771538), and China Scholarship Council (CSC) during a visit of the first author (File No. 20190604188) to Vrije Universiteit Amsterdam. The financial support is highly appreciated.

Open Access This article is licensed under a Creative Commons Attribution 4.0 International License, which permits use, sharing, adaptation, distribution and reproduction in any medium or format, as long as you give appropriate credit to the original author(s) and the source, provide a link to the Creative Commons licence, and indicate if changes were made. The images or other third party material in this article are included in the article's Creative Commons licence, unless indicated otherwise in a credit line to the material. If material is not included in the article's Creative Commons licence and your intended use is not permitted by statutory regulation or exceeds the permitted use, you will need to obtain permission directly from the copyright holder. To view a copy of this licence, visit http://creativecommons. org/licenses/by/4.0/.

\section{References}

Albarello, D., and V. D'Amico. 2004. Attenuation relationship of macroseismic intensity in Italy for probabilistic seismic hazard assessment. Bollettino di Geofisica Teorica ed Applicata 45(4): $271-284$

Anagnos, T., and A.S. Kiremidjian. 1988. A review of earthquake occurrence models for seismic hazard analysis. Probabilistic Engineering Mechanics 3(1): 3-11.

Argyroudis, S., and A.M. Kaynia. 2015. Analytical seismic fragility functions for highway and railway embankments and cuts. Earthquake Engineering \& Structural Dynamics 41(11): 1549-1568.

Argyroudis, S., J. Selva, P. Gehl, and K. Pitilakis, 2015. Systemic seismic risk assessment of road networks considering interactions with the built environment. Computer-Aided Civil and Infrastructure Engineering 30(7): 524-540.

Arrighi, C., F. Tarani, E. Vicario, and F. Castelli. 2017. Flood impacts on a water distribution network. Natural Hazards and Earth System Sciences 17(12): 2109-2123.

Baker, J.W. 2008. An introduction to probabilistic seismic hazard analysis (PSHA). Version 1.3. https://web.stanford.edu/
bakerjw/Publications/Baker_(2008)_Intro_to_PSHA_v1_3. pdf. Accessed 1 Feb 2020.

CEA (China Earthquake Administration). 2015. Seismic ground motion parameters zonation map of China, GB 18306-2015. Beijing: CEA (in Chinese).

Cornell, C.A. 1968. Engineering seismic risk analysis. Bulletin of the Seismological Society of America 58(5): 1583-1606.

Douglas, J. 2019. Ground motion prediction equations 1964-2019. Peer report. http://www.gmpe.org.uk/gmpereport2014.pdf. Accessed 10 Feb 2020.

Edwards, F.L., D.C. Goodrich, M. Hellweg, J.A. Strauss, M. Eskijian, and O. Jaradat. 2015. Great East Japan Earthquake, JR East mitigation successes, and lessons for California high-speed rail. San José, CA: Mineta Transportation Institute, San José State University. https://transweb.sjsu.edu/sites/default/files/1225great-east-japan-earthquake-lessons-for-California-HSR.pdf. Accessed 10 Mar 2020.

Gong, M., Y. Wang, S. Wang, and W. Liu. 2017. Enhancing robustness of interdependent network under recovery based on a two-layer-protection strategy. Scientific Reports 7(1): Article 12753.

Grossi, P. 2005. Catastrophe modeling: A new approach to managing risk. New York: Springer.

Hall, J.W., R.J. Dawson, P.B. Sayers, C. Rosu, J.B. Chatterton, and R. Deakin. 2003. A methodology for national-scale flood risk assessment. Proceedings of the Institution of Civil Engineers: Water and Maritime Engineering 156(3): 235-247.

Huang, C., and Z.S. Nivolianitou. 2019. Risk analysis based on data and crisis response beyond knowledge. In Proceedings of the 7th International Conference on Risk Analysis and Crisis Response, ed. C. Huang, and Z.S. Nivolianitou, 550-556. Athens: CRC Press.

Irwansyah, E., E. Winarko, Z.E. Rasjid, and R.D. Bekti. 2013. Earthquake hazard zonation using peak ground acceleration (PGA) approach. Journal of Physics: Conference Series 423(1): $1-9$.

Kappos, A., A. Sextos, S. Stefanidou, G. Mylonakis, M. Pitsiava, and G. Sergiadis. 2014. Seismic risk of inter-urban transportation networks. Procedia Economics and Finance 18: 263-270.

Kilanitis, I., and A. Sextos. 2019. Integrated seismic risk and resilience assessment of roadway networks in earthquake prone areas. Bulletin of Earthquake Engineering 17(1): 181-210.

Kiremidjian, A., J. Moore, Y.Y. Fan, O. Yazlali, N. Basoz, and M. Williams. 2007. Seismic risk assessment of transportation network systems. Journal of Earthquake Engineering 11(3): 371-382.

Koks, E.E., and M. Thissen. 2016. A multiregional impact assessment model for disaster analysis. Economic Systems Research 28(4): 429-449.

Koks, E.E., J. Rozenberg, C. Zorn, M. Tariverdi, M. Vousdoukas, S.A. Fraser, J.W. Hall, and S. Hallegatte. 2019. A global multihazard risk analysis of road and railway infrastructure assets. Nature Communications 10(1): 1-11.

Liu, K., M. Wang, Y. Cao, W. Zhu, J. Wu, and X. Yan. 2018a. A comprehensive risk analysis of transportation networks affected by rainfall-induced multihazards. Risk Analysis 38(8): $1618-1633$.

Liu, K., M. Wang, Y. Cao, W. Zhu, and G. Yang. 2018b. Susceptibility of existing and planned Chinese railway system subjected to rainfall-induced multi-hazards. Transportation Research Part A: Policy and Practice 117: 214-226.

Merz, M., M. Hiete, T. Comes, and F. Schultmann. 2013. A composite indicator model to assess natural disaster risks in industry on a spatial level. Journal of Risk Research 16(9): 1077-1099. 
Mohanty, W.K., R. Prakash, G. Suresh, A.K. Shukla, M. Yanger Walling, and J.P. Srivastava. 2009. Estimation of coda wave attenuation for the national capital region, Delhi, India using local earthquakes. Pure and Applied Geophysics 166(3): 429-449.

Nekrasova, A., V.G. Kossobokov, I.A. Parvez, and X. Tao. 2015. Seismic hazard and risk assessment based on the unified scaling law for earthquakes. Acta Geodaetica et Geophysica 50(1): 21-37.

Padgett, J.E., R. Desroches, and E. Nilsson. 2010. Regional seismic risk assessment of bridge network in Charleston, South Carolina. Journal of Earthquake Engineering 14(6): 918-933.

Pan, H., Y. Jin, and Y.X. Hu. 2003. Discussion about the relationship between seismic belt and seismic statistical zone. Acta Seismologica Sinica English Edition 16(3): 323-329.

Park, J., and E. Choi. 2011. Fragility analysis of track-on steel-plategirder railway bridges in Korea. Engineering Structures 33(3): 696-705.

Pregnolato, M., A. Ford, V. Glenis, S. Wilkinson, and R. Dawson. 2017. Impact of climate change on disruption to Urban transport networks from pluvial flooding. Journal of Infrastructure Systems 23(4): 1-11.

Scholz, C.H. 1968. The frequency-magnitude relation of microfracturing in rock and its relation to earthquakes. Bulletin of the Seismological Society of America 58(1): 399-415.

Sen, P., S. Dasgupta, A. Chatterjee, P.A. Sreeram, G. Mukherjee, and S.S. Manna. 2003. Small-world properties of the Indian railway network. Physical Review E-Statistical Physics, Plasmas, Fluids, and Related Interdisciplinary Topics 67(3): 1-5.
Speight, L.J., J.W. Hall, and C.G. Kilsby. 2017. A multi-scale framework for flood risk analysis at spatially distributed locations. Journal of Flood Risk Management 10(1): 124-137.

UNCRD (United Nations Centre for Regional Development). 2008. 2008 China Sichuan earthquake investigation report. https:// www.recoveryplatform.org/assets/publication/UNCRD_

Sichuan_Report_2009_CN.pdf. Accessed 5 Mar 2020 (in Chinese).

Winsemius, H.C., L.P.H. Van Beek, B. Jongman, P.J. Ward, and A. Bouwman. 2013. A framework for global river flood risk assessments. Hydrology and Earth System Sciences 17(5): 1871-1892.

Wu, J., N. Li, S. Hallegatte, P. Shi, A. Hu, and X. Liu. 2012. Regional indirect economic impact evaluation of the 2008 Wenchuan Earthquake. Environmental Earth Sciences 65(1): 161-172.

Yamano, N., Y. Kajitani, and Y. Shumuta. 2007. Modeling the regional economic loss of natural disasters: The search for economic hotspots. Economic Systems Research 19(2): 163-181.

Yan, Y., L. Hong, X. He, M. Ouyang, S. Peeta, and X. Chen. 2017. Pre-disaster investment decisions for strengthening the Chinese railway system under earthquakes. Transportation Research Part E: Logistics and Transportation Review 105: 39-59.

$\mathrm{Yu}, \mathrm{Y}$. 2015. Establishment and characteristic qnalysis of attenuation relations of ground motion parameters in new generation seismic zoning maps. City and Disaster Reduction 3: 34-38 (in Chinese).

Zuur, G., R.J. Fryer, R.S.T. Ferro, and T. Tokai. 2001. Modelling the size selectivities of a trawl codend and an associated square mesh panel. ICES Journal of Marine Science 58(3): 657-671. 